\section{Transient, unilateral, complete, oculomotor palsy in an adult patient with idiopathic intracranial hypertension}

\author{
IVO BEKAVAC • SANGEETA GOEL
}

IVO BEKAVAC $(\square)$

Department of Neurology Cedar Valley Medical Specialists

1753 West Ridgeway Avenue Suite 112, Waterloo, lowa 50701, USA Phone: (319) 833-5954

Fax: (319) 833-5955

E-mail: neuromarina@aol.com

SANGEETA GOEL

Department of Neurology Covenant Hospital, Waterloo lowa, USA

\begin{abstract}
Idiopathic intracranial hypertension $(\mathrm{IIH})$ is a well recognized condition of elevated intracranial pressure of unknown cause. Many etiologies have been proposed, but few-besides a high body mass index, hypervitaminosis A, steroid withdrawal, exposure to tetracyclines and female gender- have been proven. The main morbidity in this condition is visual loss and is often reversed if recognized early and treated promptly with weight- reduction, a low-sodium diet and acetazolamide.
\end{abstract}

Key words: idiopathic intracranial hypertension, oculomotor palsy, headache, adult

\section{Introduction}

Idiopathic intracranial hypertension $(\mathrm{IIH})$, also known as pseudotumor cerebri, is a clinical condition of elevated intracranial pressure of unknown etiology. Typical presentation consists of daily headache, pulse-synchronous tinnitus, transient blurred vision, papilledema with associated visual loss, and diplopia from abducens nerve paresis. (1)

Several conditions have been suspected, but only a few, including obesity and weight gain during the 12 months before diagnosis, steroid withdrawal, female gender, hypervitaminosis A and related compounds, have been proven. (2-4)

The treatment is focused on the correction of the presumed cause, including a low-sodium diet, diuretics and a weight-reduction program. (5)

To our knowledge, we describe, possibly, the first adult patient with complete oculomotor palsy.

\section{Case report}

A 53-year old, right-handed woman presented with an acute onset of sharp pain involving the top of her head associated with nausea, vomiting, photo and pnonophobia two weeks prior to her neurological visit. At that time she was hospitalized and treated symptomatically for headache. During the patient's hospitalization, left ptosis was noticed by her primary doctor.

Initial metabolic work-up was unremarkable and an MRI (magnetic resonance imaging) was performed, remarkable for a partially empty sella, not reported by the radiologist (figure 1). No other abnormalities were seen. Cavernous sinus was normal and no abnormal enhancement with gadolinium was seen.

The patient had been headache free for an entire week prior to her neurological exam, and the only complaint she had was not being able to elevate her left eyelid. She denied any fever, visual obscuration, diplopia or tinnitus.

Past medical history was remarkable for migrainous headaches, (she had been headache free for years prior to this event), hypertension and depression.
While being on the antidepressant, venlafaxine, she has gained 45 pounds during the previous 12 months.

Physical exam revealed 5'8"' height, 228 pounds weight, blood pressure of 150/90 $\mathrm{mm} \mathrm{Hg}$ and regular heart rate of 70 .

Fundoscopic examination revealed grade III papilledema OS (left eye), grade II OD (right eye). There was no ocular or carotid bruit. The cardiac examination was normal, without murmur. Neurological examination was remarkable for complete left ptosis, mydriasis, light stimulation revealed OS $5 \mathrm{~mm}$ down to $4 \mathrm{~mm}$, OD $3 \mathrm{~mm}$ down to $2 \mathrm{~mm}$, normal abduction and complete palsy of occulomotor innervated muscles on the left.

Right extraocular motor activity was entirely normal. No visual field defect was detected.

An emergent magnetic resonance angiogram (MRA) and venogram (MRV) were obtained without any abnormalities. In particular, there was no evidence of intracranial aneurysm or venous sinus thrombosis.

Subsequently, the same day a spinal tap was performed and revealed ele- 
vated intracranial pressure of $420 \mathrm{~mm}$ water. Closing pressure was $100 \mathrm{~mm}$ water after $30 \mathrm{ml}$ of clear cerebrospinal fluid (CSF) was removed. Analysis of CSF was normal, cytology was also normal, no malignant cells were found. The repeated metabolic workup, including sederate, $\mathrm{C}$ - reactive protein and antinuclear antibodies was normal.

The patient was immediately started on acetalozamide 500 mg twice daily, a weight reduction program and instructed to contact her psychiatrist regarding stopping venflaxine and starting another antidepressant. The patient's symptoms resolved two weeks later, with no residual left oculomotor deficit and normal pupillary response.

\section{Discussion.}

The annual incidence of $\mathrm{IIH}$ is $0.9 / 100$ 000 persons and 3.5/100 000 in females 15 to 44 years old. Among obese women the incidence is $19 / 100$ 000. (6) More than $90 \%$ of IIH patients are obese and more than $90 \%$ are women of childbearing age. Female preponderance and the association of obesity is true only for postpubertal patients. (7)

The mean age at diagnosis is 30 years. (6) There have been no reports of venflaxine induced $\mathrm{IH}$, but it can produce weight gain. (8)

The most accepted hypothesis is that $\mathrm{IIH}$ is a syndrome of reduced CSF absorption and current analysis has concluded that histological features of the brain are normal. (9)
The presenting symptoms are headaches in $94 \%$ of patients, transient visual obscuration in $68 \%$, pulse synchronous tinnitus in 58\%, photopsia in 54\% and retrobulbar pain in 44\%. (10-14) Diplopia, which occurs in $38 \%$ of patients due to abducens nerve paresis, (15) and loss of vision, occurring in $30 \%$ of patients, (16) are less common.

The major signs of $\mathrm{IH}$ are papilledema and paresis of the abducens nerve. $(16,17)$
This case report raises several important issues. First, even a relatively late onset of headaches (after age 50) and signs of oculomotor nerve paresis must raise the suspicion of $\mathrm{IH}$ if other etiologies have been previously excluded, such as an intracranial aneurysm or any other compressive lesion. Second, despite the "empty sella" abnormality on MRI, very often underreported by an interpreting radiologist, and if reported usually interpreted of no clinical

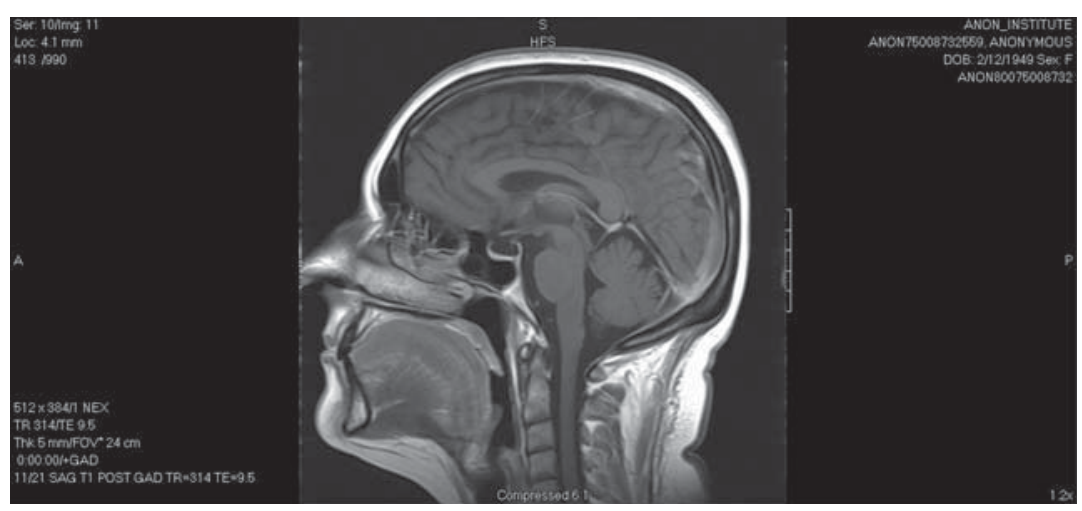

Figure 1. Sagital MRI of the brain with gadolinium shows a partially empty sella.

We are aware of just a few clinical reports of $\mathrm{IH}$ and oculomotor nerve involvement in the pediatric population, $(18,19)$ and two additional patients have been reported, but age was unknown at the onset $(20,21)$ with sparing of pupillary fibers in all described cases. There has been no single report of complete oculomotor palsy to our knowledge. significance, it might be, in a particular setting, very important information. $(22,23)$ Third, even though there have been no previous reports of venflaxine induced $\mathrm{IH}$, we still believe the underlying mechanism is weight gain; this possibility cannot be completely excluded. Fourth, prompt diagnosis of $\mathrm{IH}$ can reverse a patient's symptoms and signs. 


\section{REFERENCES}

1. Wall M. Idiopathic intracranial hypertension (pseudotumor cerebri). Curr Neurol Neurosci Rep 2008 Mar;8(2):87-93.

2. Digre KB, Corbett JJ. Pseudotumor cerebri in men. Arch Neurol 1988;45:866-72.

3. Ireland B, Corbett J, Wallace RB. The search for causes of idiopathic intracranial hypertension. A preliminary case-control study. Arch Neurol 1990;47:315-20.

4. Giuseffi V, Wall M, Siegel PZ, Rojas PB. Symptoms and disease associations in idiopathic intracranial hypertension (pseudotumor cerebri): a case-control study. Neurology 1991;41:239-44.

5. Wall M, Weisberg LA. Treatment of pseudotumor cerebri. In: Johnson RT, ed. Current Therapy in Neurologic Disease. Philadelphia: BC Decker; 1984. p. 226-30.

6. Durcan FJ, Corbett JJ, Wall M. The incidence of pseudotumor cerebri. Population studies in lowa and Louisiana. Arch Neurol 1988;45:875-7.

7. Balcer LJ, Liu GT, Forman S, Pun K, Volpe NJ, Galetta SL, et al. Idiopathic intracranial hypertension: relation of age and obesity in children. Neurology 1999;52:870-2.

8. Harrison CL, Ferrier N, Young AH. Tolerability of high-dose venflaxine in depressed patients. J Psychopharmacol 2004 Jun; 18(2):200-4

9. Wall M, Dollar JD, Sadun AA, Kardon R. Idiopathic intracranial hypertension: Lack of histological evidence for cerebral edema. Arch Neurol 1995;52:141-5.

10. Sadun AA, Currie JN, Lessell S. Transient visual obscurations with elevated optic discs. Ann Neurol 1984:16:489-94.

11. Bulens C, Meerwaldt JD, Koudstaal PJ, van der Wildt GJ. Spacial contrast sensitivity in benign intracranial hypertension. J Neurol Neurosurg Psychiatry 1988;51:1323-9.

12. Corbett JJ. The 1982 Silverside lecture. Problems in the diagnosis and treatmentof pseudotumor cerebri. Can J Neurol Sci 1983;10:221-9.

13. Rush JA. Pseudotumor cerebri: clinical profile and visual outcome in 63 patients. Mayo Clin Proc 1980;55:541-6.

14. Meador KJ, Swift TR. Tinnitus from intracranial hypertension. 1984;34:1258-61.

15. Sismanis A. Otologic manifestations of benign intracranial hypertension syndrome: diagnosis and management. Laryngoscope 1987;97(Suppl42)1-17.

16. Wall M, White WN II. Asymmetric papilledema in idiopathic intracranial hypertension: prospective interocular comparison of sensory visual function. Invest Ophthalmol Vis Sci 1998;39:134-42.

17. Wall M, George D. Idiopathic intracranial hypertension. A prospective study of 50 patients. Brain 1991;114:155-80.

18. Thapa R, Mukherjee S. Transient bilateral oculomotor palsy in pseudotumor cerebri. J Child Neurol 2008 May;23(5):580-1.

19. Chansoria M, Agrawal A, Ganghoriya P, Raghu Raman B. Pseudotumor cerebri with transient oculomotor palsy. Indian J Pediatr 2005 Dec;72(12):1047-8.

20. Bruce BB, Newman NJ, Biousse V. Ophthalmoparesis in idiopathic intracranial hypertension. Am J Ophthalmol 2006 Nov;142(5):878-80.

21. McCammon A, Kaufman HH, Sears ES. Transient oculomotor paralysis in pseudotumor cerebri. Neurology 1981 Feb;31(2):182-4.

22. Zagardo MT, Cail WS, Kelman SE, Rothman MI. Reversible empty sella in idiopathic intracranial hypertension: an indicator of successful therapy? AJNR 1996 Nov-Dec;17(10):1953-6.

23. Lim MJ, Pushparajah K, Jan W, Calver D, Lin JP. Magnetic resonance imaging changes in idiopathic intracranial in children. J Child Neurol 2010 Mar;25(3):294-9. 